\title{
Once para miles. Fútbol, poder e identidades colectivas en España (1900-2020)
}

Eleven for thousands. Soccer, Power and Collective Identities in Spain (1900-2020)

\author{
Vicent Flor \\ Universitat de València
}

\section{RESUMEN}

En este artículo se analizan diversas de las claves en la relación entre el fútbol y el poder y las identidades colectivas, particularmente en la España de los siglos XX y XXI. La tesis del artículo es que, a pesar de los que afirman que no hay que mezclar poder y deporte, ambos están extraordinariamente imbricados y, en concreto, que la política de los estados-nación utiliza el deporte como espacio de nacionalización de masas.

PALABRAS CLAVE: deporte, fútbol, identidad, poder, nacionalismo

\section{ABSTRACT}

This paper analyzes several of the keys of the relationship between football and collective and political identities, particularly at Spain in the 20th and 21st centuries. The thesis of the paper is, despite those who affirm that power and sport shouldn't be mixed, both are extraordinarily entangled and, specifically, and the politics of the nation-states uses sport for mass nationalization.

KEY WORDS: sport, football, identity, power, nationalism 


\section{INTRODUCCIÓN: EL FÚTBOL COMO HERRAMIENTA PARA EL ANÁLISIS SOCIAL}

El deporte y, en concreto, el fútbol tardó en ser aceptado como objeto de estudio relevante para las ciencias sociales (Dunning 1999: 11-13). De hecho, "el deporte no era $-\mathrm{o}$, tal vez, para decirlo con más exactitud, los 'padres fundadores' no consideraron que era- el locus de problemas sociales serios en la época en que estaban definiéndose los perfiles básicos de la sociología moderna" (Elias y Dunning 2016: 40).

Por otra parte, durante décadas hubo una visión excesivamente negativa de este deporte. Incluso fue percibido como un pasatiempo para desviar la atención de los obreros de sus intereses de clase y, explícitamente, como una "droga social". Sin embargo, los deportes y los espectáculos de masas son una actividad importante de las sociedades modernas. Y, por tanto, su análisis debería de contribuir a entender nuestras sociedades. Si nadie cuestiona que las fábricas, las escuelas o hasta los templos son espacios para la comprensión de lo social, lo mismo podría decirse de los estadios deportivos que, hasta la pandemia del COVID-19, seguían contando con una gran afluencia de espectadores. Al fin y al cabo, "ha sido el pasatiempo preferido de las clases populares durante los últimos 120 o 130 años" (Fernández 2020: 18). Y, en España, "el fútbol siguió siendo el pasatiempo más popular del país y actuó como instrumento clave en el proceso de renovación cultural de la nación española" (Quiroga 2014: 242). Finalmente, la sociología del deporte ha acabado siendo aceptada como parte de la disciplina, aunque sigue ocupando una posición periférica, como lo ocupa la sociología del ocio.

En cualquier caso, si para muchas personas el deporte es importante, ¿quién somos los analistas sociales para considerar que no lo es o que están a priori alienados? ¿No podemos entenderlos mejor observándolos en los estadios o en los bares reunidos ante una pantalla? Los humanos, además de seres racionales, también somos pasionales, sentimentales o emocionales y no parece que las emociones no formen parte de lo social.

Sin ningún género de dudas, el fútbol es mucho más que un juego que practican varios jugadores con el objetivo de introducir una pelota en la portería contraria: se ha convertido, con mucha diferencia, en el deporte más popular, más practicado y seguido del planeta, en Europa y fuera de Europa. A pesar de que nació en el continente que creó el colonialismo, desde África, América, Asia y, 
aunque menos, también Oceanía se vibra con el balón en movimiento. A modo de ejemplo,

\begin{abstract}
en cualquier país africano, si juega la selección nacional o el club de la región, todo se paraliza. Durante 90 minutos de pasión se olvidan los problemas territoriales, las injusticias del pasado, los abusos coloniales, las luchas internas entre vecinos, los enfrentamientos tribales [...] El gol deviene el refugio de los atormentados (Edjogo-Owono 2019: 14).
\end{abstract}

El fútbol, en consecuencia, no es solo fútbol. A pesar de que algunos políticos y periodistas defensores del statu quo argumentan que sería solo un deporte y que, por tanto, no se tendría que "politizar" (en realidad, quieren decir que no se tiene que usar contra este statu quo pero sí a favor. Y continuadamente), lo cierto es que es algo más que un simple juego. Y cabe añadir que sin este plus el fútbol no tendría tantos seguidores ni practicantes. Entre otras cosas, es un importante mecanismo de socialización (y particularmente masculino infantil y juvenil), un ritual colectivo periódico y un potente identificador grupal resultado de los enfrentamientos agonales que suponen los partidos, singularmente los de competición. Es, en definitiva, lo que Marcel Mauss consideró un hecho social total, que no se puede reducir solo a las esferas económica o política, sino que atraviesa varios campos.

\title{
FUNDAMENTOS DEL TRABAJO Y ESPECIFICACIÓN DE LOS OBJETIVOS, FUENTES Y METODOLOGÍA
}

Este artículo tiene como objetivo mostrar que los campos del deporte y del poder, y específicamente en España, son autónomos pero se presentan muy interrelacionados y generan simbiosis. Se partirá, pues, de la visión de que el deporte es un campo social autónomo y no un mero apéndice de la política. Al fin y al cabo, "los juegos son en gran medida fines en sí mismos. Su propósito, si es que tiene alguno, es dar placer a la gente" (Elias y Dunning 2016: 272). Gerald Ford, el 38 Presidente de los Estados Unidos de América declaró que "un acontecimiento deportivo puede servir a una nación tanto como una victoria militar", lo que da idea de la importancia que tiene el deporte de masas. Por tanto, el fútbol y la política son "inheremente indistinguibles" (Correia 2019: 11), aunque esta relación todavía está investigada de manera insuficiente en España. 
En este artículo se intentarán poner algunas bases para la comprensión de la interrelación del campo deportivo y el campo político.

Para ello, se hará un análisis del discurso de élites políticas y deportivas para comprehender la correlación entre ambos campos. Metodológicamente se complementará con estudios demoscópicos. Cabe reseñar que en España los investigadores contamos con datos cuantitativos insuficientes, lo que, lógicamente, dificulta su estudio. Como fuentes de este artículo se ha utilizado los estudios números 3217, 3029 y 2705 del Centro de Investigaciones Sociológicas.

\section{EL FÚTBOL Y SUS METÁFORAS}

Ciertamente el fútbol se puede interpretar de maneras diferentes. Considero que determinadas posiciones reduccionistas como "opio del pueblo" (Brohm 1999) no solo son inexactas sino que no son útiles para entenderlo. Muchas de las visiones negativas del fútbol han procedido, precisamente, de intelectuales, que lo han demonizado (Vázquez Montalbán 1999: 50) y, en concreto, de la izquierda política, que vio al principio los deportes de competición como espectáculos capitalistas (Viñas 2019: 88). Sin embargo, "ni por sus orígenes ni por sus diferentes características se puede definir al fútbol como simple instrumento de manipulación de unos por los otros" (Augé 1999: 59). Por otra parte, tampoco son útiles determinadas visiones maniqueas. De hecho,

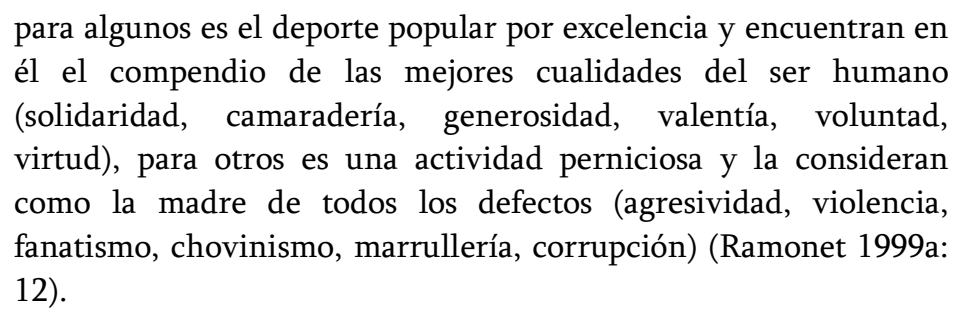

$\mathrm{Ni}$ quienes practican fútbol ni quienes siguen a un equipo son personas necesariamente con alguna carencia o déficit: "los amantes del fútbol no son “idiotas culturales" (Bromberger 1999: 29). Tampoco conforman masas indiferenciadas (ni incluso dentro de los estadios donde, atendiendo a la clasificación de las gradas por precio de entradas y/o por proximidad a la lonja presidencial o por otros criterios, usualmente encontramos sectores más de clases medianas y altas y otros más populares). 
El deporte y, en concreto, el fútbol, pues, tiene que ser visto de manera no simplista. Si ha sido una práctica y un espectáculo tan masivo debe ser porque, de alguna manera, conecta (y representa) a las sociedades modernas. Pero, ¿de qué manera lo haría? Algunos han identificado el fútbol con dos metáforas que pueden ser iluminadoras, pero con las que hay que ir con cautela. Estas han sido el fútbol como "guerra" (Ramonet 1999b) y como "religión" o "religión laica" (Hobsbawm 1979, Augé 1999).

Ciertamente, el fútbol profesional es competición y, por lo tanto, victorias y derrotas. Y una parte del ritual y del lenguaje de este deporte toma prestado lenguaje bélico. En los partidos internacionales se interpretan himnos nacionales, ondean banderas nacionales y a menudo representantes de los estados ocupan las tribunas. Además, los equipos no solo "atacan" y "defienden" sino que "disparan" a portería, "conquistan" títulos o estadios, "aplastan" a rivales, etc. Mario Alberto Kempes era conocido como "el matador" por su capacidad goleadora. Se puede escuchar con relativa frecuncia a locutores españoles usar la expresión "un Madrid imperial" cuando juega bien el Real Madrid (RM) un tramo de un partido. Aun así, los ciento cincuenta años aproximadamente de fútbol moderno se han visto salpicados por muchas guerras, una parte importante de ellas extraordinariamente cruentas. No parece, por tanto, que haya sustituido a la guerra ni sea propiamente una guerra a pesar de que, como se verá, cierta violencia no le ha sido ajena. De hecho, "el fútbol es diametralmente opuesto a la guerra [...] Por más que determinados equipos se entiendan como enemigos irreconciliables, no hay en ningún caso un anhelo de desaparición del otro. Sin él no hay partido" (Reguera 2008: 68).

El escritor Eduardo Galeano, en un sentido, sin embargo, muy diferente, lo consideró una "guerra danzada", es decir, una liturgia que asume retórica y simbología bélica, pero incruenta, al fin y al cabo, una sublimación ritual de la guerra (1995: 18).

¿Sería, en cambio, el fútbol una especie de religión? En cierta medida sí, puesto que religa e identifica a determinados grupos sociales. Pero, a lo sumo, sería una religión sin dioses, con rituales periódicos y repetitivos y templos que dotan de sentido a los feligreses (Augé 1999). Aun así, hay que ir alerta con llevar estas metáforas demasiado lejos. 


\section{EL FÚTBOL COMO "REALIDAD SOCIAL" Y SÍMBOLO DE LAS SOCIEDADES MODERNAS}

A diferencia de las metáforas de la guerra y de la religión, encuentro más ajustada la consideración del fútbol como "realidad social", es decir, como representación de la modernidad y de algunas de sus contradicciones (Correia 2019: 10). Atendiendo a la limitación de espacio, apuntaré solo algunas de las cuestiones más relevantes de este aspecto.

De entrada, no creo que sea casualidad que el fútbol tenga mucho más seguidores que el tenis, por ejemplo. El fútbol es un deporte de equipo, como la mayoría de trabajos contemporáneos, lo que no significa que todos los integrantes de la plantilla son iguales: hay desigualdades (titulares y suplentes y capitanes, líderes, y "tropa") y de salarios, cosa que se acepta con normalidad. Sin embargo, ni el mejor jugador del mundo podría él solo ganar a cualquier equipo profesional. Así, a la vez que se destacan el individualismo de los jugadores "especiales" (con el nombre de los jugadores en la camiseta, galas como los Balones de Oro, etc.), también se valora la solidaridad, "el espíritu de sacrificio" y "trabajar para el equipo". Esta mezcla de individualismo, jerarquía y espíritu de equipo tiene un aire innegable a las percepciones hegemónicas de las sociedades modernas.

Es posible que la popularidad del fútbol también esté relacionada con la capacidad de encarnar la ideología capitalista $y$, en concreto, el ideal meritocrático. Cualquiera, con independencia de sus orígenes, podría alcanzar la cima con el control de la pelota. Muchos futbolistas de clase baja, fruto de la dedicación y el esfuerzo ("sudar la camiseta"), lo han logrado. Para muchos seguidores aquí estaría la prueba que esta sociedad premia el mérito y no el nacimiento. Por ello, muchos ven en los jugadores un tipo de héroes contemporáneos. Ellos lo han alcanzado, pero también podría haber sido cualquier otro si hubiera tenido las condiciones y la constancia. Ellos, por tanto, merecen el dinero que ganan y la fama que disfrutan.

Por otro lado, el fútbol profesional es competitivo, como el capitalismo. Por eso los seguidores distinguen perfectamente entre partidos amistosos y de competición. Hay dos tipos de competiciones prototípicas de naturaleza sustantivamente diferente: liga y copa. En la copa hay sorteo (y, por lo tanto, suerte o desdicha) y un rival al que tienes que vencer o quedar eliminado. Es una competición del todo o nada ( $\mathrm{y}$, por eso, posiblemente tiene más emoción). Las ligas, sin embargo, son torneos de "la regularidad". Ganar aquí depende tanto de lo que tú haces como de lo que hacen los otros. Uno puede ganar una liga o salvarse del descenso con un número de puntos que en otro caso es insuficiente. 
Triunfar aquí es, nada más y nada menos, quedar mejor que los demás. Es relativo y no absoluto. Y cabría preguntarse si esto no es análogo a lo que ocurre en el mundo de la empresa o laboral o en algunas oposiciones.

Además, a pesar de que hay normas que teóricamente se penaliza incumplir, en el fútbol, como en los negocios o la política, se hacen trampas constantes y quienes las hacen acostumbran a estar bien vistos, puesto que serían astutos o listos. Así, simular un penalti o una lesión para ganar tiempo o cualquier otra acción para tratar de engañar el árbitro ha sido una práctica habitual. Quizás la jugada más paradigmática de trampa exitosa fue la célebre "mano de Dios" de Diego Armando Maradona contra Inglaterra en los cuartos de final del Mundial de México de 1986, que otorgó la victoria a los americanos por dos a uno. La vieron millones de personas y no comportó sanción alguna, económica o moral, al pelusa. De hecho, décadas después el argentino visitó al árbitro de aquel partido, el tunecino Ali Bennaceur, y le regaló una camiseta dedicada a su "amigo eterno".

Asimismo, el fútbol es un gran espectáculo y el entretenimiento de masas, como es conocido, es fundamental en las sociedades actuales, puesto que es una respuesta ordenada a la rutina. La facturación de las industrias cinematográficas o de videojuegos da una idea de esta relevancia. El fútbol entretiene a millones de personas. Este deporte, sin embargo, no se limita a entretener, también identifica de manera apasionada con "unos colores". Y lo hace básicamente por dos motivos: en primer lugar, porque también es un arte, relativamente próximo al circo, pero con improvisación (nunca un partido es exactamente igual que otro), donde jugadores determinados son capaces de mostrar habilidades fuera de lo común y, en segundo lugar, y este es un aspecto todavía más importante, porque es un espectáculo dramático donde se desbocan emociones colectivas. En cierta medida, se podría utilizar el concepto del antropólogo Victor Turner (1974) de "drama social" para con las competiciones o incluso algunos partidos. Los seguidores practican lealtad hacia el club con el cual se identifican y se obligan con él, en las alegrías y las penas.

Ciertamente, como en el cine, los espectadores son pasivos, pero a diferencia de las proyecciones fílmicas, en los estadios estos gritan, animan, insultan, se ponen de pie, saltan, etc., actividades infrecuentes en las salas de cine. Al fin y al cabo, "es una excitación que buscamos voluntariamente. Para sentirla, a menudo tenemos que pagar. [...] dentro de ciertos límites, podamos disfrutarla con el consentimiento social del resto y con el de nuestra propia conciencia" (Elias y Dunning 2016: 121). 
Por otro lado, el fútbol es dramático porque, a pesar que se impregna de una lógica capitalista indudable y, por tanto, hay más probabibilidades de victoria según qué equipos, el azar o la fortuna intervienen de manera decisiva en el desarrollo y el resultado de muchos partidos. Este azar genera incertidumbre (de hecho, matiza el mérito) y esta es la que provoca emoción e interés (de hecho, de no ser un partido muy importante, a los propios seguidores les cuesta ver encuentros ya jugados y de los que se conoce el marcador final). Así, "durante el transcurso del juego, se puede pasar en pocos segundos del gozo a la decepción, del miedo a la esperanza, de la rabia al sentimiento de injusticia" (Correia 2019: 16). Análogamente a como en las sociedades modernas, a pesar de que un rico tiene muchas más probabilidades de triunfar que un pobre, la suerte también le puede jugar un mal pase: aún contando con los mejores médicos y disponer de más seguridad tecnológica un cáncer o un accidente le puede dejar "fuera de juego". El fútbol, como la vida, tiene un punto arbitrario.

Así, asistir en los estadios o ver partidos en casa o en bares es una forma de interrelación social con, en principio, desconocidos (a poco que sea un club importante resulta imposible conocer a todos sus seguidores) pero que son "de los nuestros". La idea de comunidad imaginada de Benedict Anderson (2005) para las naciones se ajusta también bastante bien a los clubes y a las aficiones. Esta, de hecho, otorga sentido a los seguidores. Ganar un partido, y todavía más un título, hermana. Es una victoria colectiva. Pero una derrota también lo hace. Es un dolor compartido. Por ejemplo, antes de la época de Diego Pablo Simeone en el banquillo del Atlético de Madrid (AM) la afición colchonera se identificaba con la mala suerte, con ser "el pupas", con campañas publicitarias del club incluidas. También le ocurría a la selección española antes del periodo 20082012. Se frecuentaban los discursos fatalistas, una "narrativa de la furia y del fracaso". También este "patriotismo quejumbroso, lleno de lamentos y llantos, que incluía unas fuertes dosis de auto-conmiseración (...) sirvió para que los españoles desarrollaron un vínculo emocional bastante fuerte con el equipo nacional” (Quiroga 2014: 44 y 17).

El fútbol, por tanto, es un deporte que refleja algunas de las contradicciones, políticas y culturales, de las sociedades de la modernidad tardía. No puede ser una casualidad que el fútbol guste tanto. Hay algo más "detrás" de este deporte. $\mathrm{Al}$ fin y al cabo, "el partido de fútbol se nos ofrece como una de las profundas matrices simbólicas de nuestro tiempo" (Bromberger 1999: 35). 


\section{FÚTBOL, VIOLENCIA Y POLÍTICA}

La violencia, desgraciadamente, también ha estado presente en el fútbol. Es bien conocida la final de la Copa de Europa de 1985 en el estadio Heysel de Bruselas. Centenares de heridos y treinta y nueve muertos fue el resultado de la carga de hooligans del Liverpool. El incidente más mortífero en un estadio de fútbol por violencia tuvo lugar al Estadio Nacional de Lima en mayo de 1964 en un partido clasificatorio para las Olimpiadas entre Argentina y Perú. Superó los quinientos heridos y alcanzó la cifra de trescientos veintiocho muertos, además de saqueos, vandalismo y linchamientos de policías. Otro asunto terrible fue el ataque favorecido por las fuerzas de seguridad de radicales de Al-Masry en Puerto Said en febrero de 2012 contra los ultras Ahlawy, opositores del presidente egipcio Hosni Mubarak, con resultado de setenta y cuatro asesinatos y más de doscientos heridos graves. En mayo de 1990 los seguidores radicales del Dinamo de Zagreb y de la Estrella Roja de Belgrado se enfrentaron dejando unos sesenta heridos. En España, entre otros muchos incidentes, en las últimas décadas Aitor Zabaleta y Jimmy (Francisco Javier Romero), seguidores respectivamente de la Real Sociedad y del Deportivo de A Coruña, fueron asesinados por radicales del AM.

La violencia es un fenómeno preocupante pero minoritario y posiblemente ligado a patrones de agresividad masculina (Dunning 1999: 143). Sin embargo, no se puede afirmar categóricamente que esta violencia en el fútbol esté provocada solo por varones jóvenes de clases bajas y familias desestructuradas. Sería demasiado fácil ubicar todos los violentos entre estos, pero probablemente es una imagen inexacta. Posiblemente esto se daría más en la cultura hooligan de la Inglaterra thatcheriana pero en el fútbol italiano y español también se cuenta con grupos violentos con destacada presencia de jóvenes de clases medias.

La violencia en el fútbol se concentra fundamentalmente en grupos ultra, normalmente varones jóvenes, que comparten valores como la virilidad, la valentía, el "amor incondicional" por un club, el ruido (la animación) y el consumo de alcohol que, junto con las alteridades ultras de otros clubes, generan vínculos importantes de solidaridad y de camaradería. Al final, han conseguido romper las convenciones de la dramaturgia del fútbol, al pasar de espectadores más o menos pasivos a actores protagonistas de la representación que "presionan" a los rivales y que "logran" las victorias. Por ello, se consideran la vanguardia de la afición e incluso la representación de la esencia del fútbol (against modern football), a menudo merecedora de premios, como entradas más baratas, descuentos o regalos en desplazamientos, a una supuesta mayor fidelidad. Al fin 
y al cabo, "el partido es, a los ojos de los ultras, un combate entre dos entidades en que todo vale para desacreditar el adversario" (Correia 2019: 291).

Muchos de estos grupos ultras se han visto infestados por ultraderechistas y neonazis. En la Inglaterra de finales de los setenta del siglo pasado se infliltraron militantes del British Movement, National Front, British National Party y ciertas fracciones skinheads en los ends o gradas de animación del Chelsea, Leeds United, Millway, Newcastle United, Arsenal y West Ham (Correia 2019: 263). En Italia, la extrema derecha creció en las curve de varios estadios a partir de los ochenta. En un censo de ultras de 2007, de los 529 grupos, 72 eran considerados de extrema derecha (p. 296). En España también destacaron algunos grupos ultraderechistas como los Ultra Sur (RM), Boixos Nois (FCB), Frente Atlético (AM) o Yomus (VCF).

\section{TERRITORIO Y GLOBALIZACIÓN ¿HACIA UN CAMBIO DE LAS IDENTIDADES FUTBOLÍSTICAS?}

Las aficiones futbolísticas están muy identificadas con un territorio en concreto e incluso focalizadas en un punto, el estadio, una topofilia (Walton 2001: 26), y es difícil que funcione un cambio de ubicación por intereses empresariales, hoy por hoy, como se ha producido en los Estados Unidos en algunos casos en la liga de fútbol americano o de baloncesto. Aun así, no es imposible, a pesar de que hasta ahora los escasos intentos no han sobresalido. De hecho, el Wimbledon FC, después de bajar de la Premier League en 2000, se mudó del sur de Londres a Milton Keynes, y cambió de nombre: MK Dones. Los forofos londinenses, aplastantemente en contra de esta propuesta, fundaron la AFC Wimbledon, que pasó de la novena división inglesa a participar las últimas cuatro temporadas en la League One (equivalente a la 2a B española).

En la liga española destaca el Real Club Deportivo Espanyol, que pasó de su tradicional estadio de Sarrià, al nuevo RCDE Stadium, ubicado entre los municipios de Cornellà y El Prat, pasando por un periodo entre 1997 y 2009 en el Estadio Olímpico de Montjuic. Aun así, a pesar de que habría modificado el término municipal, no habría salido del área metropolitana de Barcelona. Un caso posterior en el fútbol español fue el traslado del Ciudad de Murcia, fundado en 1999, a Granada, en 2007, transformado como Granada 74. Dos años, más tarde, en 2009, este desapareció, lo que muestra que no es fácil improvisar aficiones ni identidades. 
Si los clubes de fútbol permanecen, pues, en general, arraigados a un territorio concreto, del cual toman una identidad marcada, a pesar de las giras de clubes europeos por Asia y América en busca de nuevos ingresos, ya no está tan claro el mantenimiento de la propiedad. De hecho, se ha producido una notable desposesión de los clubes de los socios y de los forofos, en varios casos con gestión y resultados pésimos. En Inglaterra, de hecho, algún club profesional, como el Exeter City (en la League Two), ha sido reapropiado completamente por los socios gracias mayoritariamente al accionariado popular. En el Portsmouth FC, Wycombe Wanderers y el mencionado AFC Wimblendon tienen mayoría accionarial los socios. Por otro lado, el control del Manchester United por parte del ya fallecido empresario estadounidense Malcom Glazer generó oposición y la fundación de un club prptesta como el FC United of Manchester. Los Red Rebels es un club amateur que navega por la séptima división inglesa. Pero en la grada muestran con orgullo el lema Our club, our rules (Nuestro club, nuestras normas). En otros países también se han fundado clubes de fútbol "populares", como el Shamrock Rovers dublinés, el CS Lebowski florentino, el Atlético Club de Socios, un club de protesta y alternativo al AM, o el Club de Fútbol Popular Orihuela Deportivo. En diversos casos han sido una respuesta, sin embargo, a la desaparición por deudas de clubes históricos apreciados por sus aficiones.

En España el Real Decreto 1084/1991, de 5 de julio, que desarrollaba la ley estatal de deporte, obligó prácticamente a todos los clubes de fútbol profesional a convertirse en sociedades anónimas deportivas y, por tanto, a estar regidas por el control accionarial y no de los socios. De este modo, pasaban de ser asociaciones de la sociedad civil a empresas. En la exposición de motivos de este Real Decreto se argumentaba que se pretendía "el establecimiento de un marco eficaz de responsabilidad jurídica y económica para los clubes deportivos que desarrollan actividades de carácter profesional". Se argumentó que así se "sanearían" los clubes y se evitaría en el futuro la mala gestión, como si una sociedad anónima, y más de esta característica, comportara per se una buena gestión. El caso del Málaga CF, propiedad desde 2010 del Jeque Abdullah bien Nasser Al Thani, es elocuente. En 2014 la empresa Meriton Holdings Limited, que pertenece al empresario de Singapur Peter Lim, se hizo con el control del VCF. Últimamente ha generado una gran contestación en una parte importante de su afición.

Así, con un gobierno del PSOE, el fútbol español se mercantilizó. Las excepciones fueron escasas pero de gran relevancia: el RM, el FCB, el Athletic Club y el Osasuna. La justificación de esta dualidad se fundamentó en que solo estos cuatro clubes estaban "saneados" (literalmente "aquellos que, en determinados supuestos, ya han demostrado una buena gestión en el régimen 
asociativo"). Lo cierto es que la mayoría de socios de los clubes de fútbol españoles perdieron el control de su equipo en beneficio de una minoría o de una única persona, normalmente empresarios con pocos escrúpulos y que usaban los clubes como plataforma para favorecer sus negocios particulares. El proceso de reparto de acciones en más de un caso distó de ser transparente.

Sin embargo, con la globalización, a pesar de lo que sostienen algunos autores (Llopis 2006), la pasión nacional futbolística no se ha apagado precisamente. Tampoco la identificación local, regional o nacional de muchos clubes, ya que:

en España, la internacionalización de las plantillas y la conversión de los clubes en Sociedades Anónimas Deportivas (SAE) no ha perjudicado a la capacidad de adscripción identitaria de los clubes de fútbol. Una clave de esto radica que el simbolismo identitario se forja en el encuentro agonal (Llopis 2006: 62).

No en balde, en 2003 un 73\% de los españoles estaba de acuerdo con la idea que los clubes de fútbol "representaban" a la ciudad donde tenían la sede (Llopis 2006: 53). La globalización del fútbol, en particular de los europeos a raíz de la sentencia Bosman, no habría cambiado de manera significativa las identificaciones tradicionales. Por ejemplo, aunque no es infrecuente en los partidos contra el VCF entre los forofos del Levante UD escuchar el cántico "es de los chinos, el Valencia es de los chinos", la afición del VCF continúa considerando el club suyo, cosa que se ha podido comprobar en las celebraciones por el centenario del club o en el título de Copa del Rey de 2019.

En cualquier caso, está por ver si acaba de triunfar (y en qué medida lo haría) el fútbol como negocio empresarial global por encima de las propias aficiones locales en beneficio de unos nuevos aficionados que serían vistos más como clientes que como forofos. De hecho, estamos asistiendo hoy por hoy a una "brutal gentrificación de los estadios [que] va ligada con la desafección de las clases populares que, alejadas de los recintos deportivos, quedan relegadas a seguir los partidos a través de la pantalla" (Correia 2019: 14). El propio Correia se hace eco de un dato incontestable: entre 1990 y 2011 el precio de las entradas más baratas para Anfield Road, el campo del Liverpool, se incrementó en un $1.108 \%$. 


\section{FÚTBOL, PODER E IDENTIDADES}

En España, como en otros muchos estados-nación, el deporte ha devenido un fenómeno de gran interés. De hecho, continúa teniéndolo a pesar de que parece más moderado que en el franquismo, con menos oportunidades de ocio. Así, en 2018 un 31'4\% de los ciudadanos afirmaba que hacía deporte durante su tiempo de esparcimiento y un 9'7\% que asistía a algún espectáculo deportivo. ${ }^{1}$ La actividad deportiva, sin embargo, todavía estaba a mucha distancia de ir a dar un paseo o mirar la televisión. En $2014^{2}$ un 54'9\% afirmaba que estaba muy o bastante interesado en los deportes, ligeramente menos que en 2007 (59'6\%) ${ }^{3}$. De hecho, era uno de los temas que más importaba y que más generaba atención, tanto que en 2014 casi la mitad de los encuestados (46\%) declaraba tratar de estar al día de los deportes, cifra muy parecida a la política (47'3\%), la salud (46'2\%) y la cultura (447\%) pero ligeramente por debajo de la economía y del trabajo (55’\%). Significativamente, los deportes eran la materia en la que se consideraban mejor informados (20'9\%), incluso por encima de la economía (13'8\%), a pesar de la importante crisis económica, y a mucha distancia de la cultura (9'5\%). Aun así, este interés esconde diferencias sustanciales, en particular de género: mientras que las mujeres interesadas serían el 30’7\%, en los varones ascendía al 68 '7\%. En concreto, un $68^{\prime} 1 \%$ (51'4\% por lo menos una vez a la semana) afirmaba ver programas deportivos por televisión, hecho que contrasta con el 78\% de 2004 (Llopis 2006: 47-48) y que tendría que ver con un incremento de la capacidad de autonomía de los espectadores.

Por otro lado, entre los deportes, el fútbol continúa siendo, de manera muy destacada, el preferido, con un $48 \%$ de media (2014), a mucha distancia del tenis (21'6\%) y del baloncesto (17'1\%). El tópico del deporte "rey", pues, todavía parece plenamente válido. Entre los varones esta preponderancia todavía es más grande $(61 ' 1 \%, 25 \%$ y $22 ' 1 \%$ respectivamente) y entre las mujeres más matizada (35'5\%, 18'4\% y $\left.12^{\prime} 2 \%\right)$.

\footnotetext{
${ }^{1}$ Barómetro del CIS de junio de 2018 (estudio no 3217). A partir de ahora cada vez que se haga referencia a este año se referirá a este estudio.

${ }^{2}$ Barómetro del CIS de junio de 2014 (estudio no 3029). A partir de ahora cada vez que se haga referencia a este año se referirá a este estudio.

${ }^{3}$ Barómetro del CIS de mayo de 2007 (estudio no 2705). A partir de ahora cada vez que se haga referencia a este año se referirá a este estudio.
} 
Como ya se ha mencionado, el fútbol no es un simple entretenimiento ni tampoco es solo un negocio, a pesar de que lo sería cada vez más. De hecho, solo el fútbol generaría el 1’36\% del total del PIB en España. ${ }^{4} \mathrm{Y}$, según cómo, sería un negocio opaco y, cuando menos a veces, directamente un negocio sucio (Hill 2010). De hecho, en Colombia los principales clubes estarían controlados por los cárteles de la droga.

A estas alturas, pues, difícilmente alguien podría sostener con argumentos sólidos que los clubes de fútbol y, en concreto, los profesionales, son meramente entidades deportivas. A pesar de que el camino no ha sido fácil, hace décadas que ya es relativamente común en las ciencias sociales destacar la interrelación que tiene el deporte - $\mathrm{y}$ el fútbol, en concreto, como el deporte de masas con más seguidores- y las identidades colectivas (por ejemplo, Amstrong y Giulianotti 1999), más aún en un contexto de relativa pérdida de generación de identificación otros factores como el trabajo o la religión (García Ferrando 2003: 161). En 2014 hasta un 67'4\% de los españoles se identificaban con un club de fútbol, cifra significativamente superior entre los interesados por los deportes y, en concreto, por el fútbol, lo que mostraría que tiene una intensa capacidad de adscripción identitaria incluso entre aquellos a los que no los interesa este deporte. Probablemente, por eso el fútbol es un factor de provisión de sentido para muchas personas y "se convierte así en materia prima para la interpretación colectiva de los españoles, un espacio de participación social y de intercambio emocional que actual como elemento estructurador, cohesionador y generador de sentido para los que lo comparten" (Llopis 2012: 287). Al fin y al cabo,

\begin{abstract}
la competición deportiva, en sí misma, es un poderoso símbolo que, a su vez, es significante y significado, puesto que por su carácter de enfrentamiento contenido y reglado, es decir civilizado, el acto deportivo agonal permite comparar grupos, dirimir rivalidades y establecer jerarquías, lo cual hace que su significado, más allá del hecho deportivo en sí, se vea ampliado continuamente con contenidos no estrictamente deportivos: la superioridad racial, o de un determinado sistema político sobre otro, sentimientos xenófobos, rivalidades regionales o entre pueblos, etcétera (García Ferrando 2003: 639).
\end{abstract}

\footnotetext{
4 Y supondría 185.000 puestos de trabajo. Además, el sector de la hostelería, el transporte y el alojamiento que conllevaba generó en la temporada 2016/2017 2.398 millones de euros. La Vanguardia, 10-07-2019:

https://www.lavanguardia.com/deportes/futbol/20190710/463408380300/futbol-

impacto-economico-pib-empleo.html, consulta en noviembre de 2020.
} 
El fútbol, pues, identifica y crea comuniones que se ritualizan periódicamente. Estas identificaciones pueden ser de todo tipo y, en concreto, de clase (o grupo) social, de hábitat (central o periférico), étnicas o nacionales, entre otros. Estos rituales generan símbolos colectivos cargados de energía emocional (Collins 2005). Si algo es el futbol, sobre todo en los estadios, es energía que se desborda.

A pesar de que normalmente las bases sociales de las aficiones de los equipos de fútbol acostumbran a ser heterogéneas, determinados clubes, en una coyuntura determinada (es importante tener presente que las identidades se transforman y no son inmutables), pueden asociarse con más o menos intensidad a determinados grupos sociales o ideológicos. En concreto, en el eje ideológico izquierda-derecha el Livorno italiano o el Rayo Vallecano español cuentan con unas graderías de animación (o una parte cuando menos) más identificadas con la izquierda (otra cosa son las direcciones de los clubes). En este asunto destaca el FC Sankt Pauli de Hamburgo, identificado con los valores del antifascismo, el antirracismo, el antisexismo y la antihomofobia a pesar de que esta asunción programática es relativamente reciente en la historia del club (fue fundado por burgueses) y no fue sencilla. De hecho, también contaron en el pasado con seguidores neonazis (Viñas y Parra 2017).

A veces, clubes de una misma ciudad y con una gran rivalidad representan identidades diferentes, a pesar de que hay que ir con cautela con afirmaciones categóricas. Sería el caso de la Juventus, asociada primeramente a la burguesía (el club de la Fiat) y el Torino, identificado con el proletariado, aunque con el tiempo y la identificación masiva de inmigrantes del sur con la Juve, se habría convertido en un club italiano mientras que el Torino un club auténticamente turinés (y piamontés). En la Bulgaria poscomunista el CSKA de Sofia y el Lokomotiv Plovdiv rivalizan con los más derechistas Levski y Botev respectivamente. En cualquier caso, los clubes o aficiones mayoritariamente de izquierdas en general serían minoritarios y los futbolistas que se reivindican como tales también (Peinado 2013), lo cual es significativo.

Otras veces, las rivalidades presentan un factor religioso o de minorías territoriales. El estado fundador del fútbol no ha sido precisamente ajeno a este tipo de enfrentamientos, entre los cuales destaca el de los dos históricos de Glasgow, el Celtic y los Rangers. El historiador Eric Hobswawm también incluía otras rivalidades como las del Sheffield United con el Sheffield Wednesday, Nottingham Forest y Nottingham County e incluso Liverpool contra Everton y consideraba que esta 
oposición deportiva se superpone a veces con una oposición entre católicos y protestantes o irlandeses y no irlandeses en las ciudades con minorías nacionales o confesionales (1979).

También una misma ciudad puede expresar rivalidades estrictamente políticas, en concreto entre clubes a favor de un régimen determinado (o directamente parte de él) y clubes que no o en contra de este régimen. Es relativamente conocido el antagonismo en Moscú durante la época soviética entre el Dinamo, el CSKA $^{5}$ y el Spartak, el equipo del pueblo (Curletto 2018), que tendría un manera de jugar más imprevisible e improvisada frente a la orden y la disciplina del Dinamo, al final dos modelos diferentes de masculinidad (Correia 2019: 112).

Las identificaciones políticas de todo tipo se producen también fuera del continente europeo. A modo de ejemplo, puede servir el enfrentamiento entre el Al Faisaly, equipo donde predominan los jordanos, y el Ay Uihdat, cuyos jugadores son mayoritariamente refugiados palestinos:

en los años en que se prohibió toda actividad política, la tensión existente entre ambas comunidades cristalizó en la feroz rivalidad que mantenían dos equipos de fútbol [...] Tras la subida al trono del rey Abdulá, los seguidores de Al Faisaly se burlaban de sus rivales en el estadio pidiendo con cánticos al monarca que se divorciase de su esposa, la reina Rania, que es de origen palestino. [...] ¿¿De dónde es ella? ¿De dónde es? Divórciate, divórciate, oh, padre de Husein’ [...] En otro cántico le pedían a Israel que reforzase su ejército" (MacFarquhar 2010: 214-215).

No es de extrañar, pues, que el fútbol haya sido utilizado por los regímenes políticos para legitimarse, pero también por las ideologías contrahegemónicas para intentar afirmarse y oponerse. Los estadios, pues, pueden ser coliseos para glorificar personajes políticos (sea un primer ministro, un monarca o un

\footnotetext{
${ }^{5}$ El Dinamo, refundado a partir del OKS, dominador histórico del fútbol ruso, fue controlado a partir de 1923 por el Ministerio del Interior y la KGB, con sus diferentes nombres. De hecho, Lavrenti Béria fue un presidente honorífico muy implicado con el club. El CSKA pertenecía al Ejército Rojo.
} 
dictador) como para criticar a los regímenes existentes. ${ }^{6}$ De hecho, gracias a cierto anonimato que proporcionaba la asistencia masiva, diversos partidos fueron aprovechados para manifestar oposición: en la URSS apoyar al Spartak de Moscú era "una pequeña manera de decir 'no"' (Correia 2019: 113); en la Alemania nazi hubo resistencia deportiva, como rehusar hacer el saludo fascista, cajas de solidaridad con detenidos, pegadas de carteles, etc. e incluso se apaleó a un árbitro nazi, además de cánticos antialemanes y lanzamientos de objetos en Austria (p. 128 y p. 132); en Irán se criticó a Jomeini a principio de los ochenta del siglo pasado (Ramonet 1999b: 132) y, entre otros, gracias al club SC Corinthians o a los Ultras Ahlawy del Al-Ahly SC se combatieron las dictaduras brasileña y egipcia, respectivamente (Correia 2019: 143-172).

Sin embargo, el fútbol oficial intenta evitar los mensajes considerados políticos en los estadios (como si no fuera político agitar una bandera de un estado-nación o condenar el racismo), por medio de sanciones y de multas económicas. Por ejemplo, el Celtic de Glasgow fue condenado porque la Green Brigade ondeó banderas palestinas en Celtic Park en un partido en verano de 2016 de fase previa de la Liga de Campeones contra el israelí Hapoel Be’er Sheva. Aún con todo no será sencillo despolitizar el fútbol puesto que los partidos no son solo once contra once sino que "juegan" miles contra miles de personas. En el fútbol también entran en juego unos "colores", es decir, identificaciones colectivas.

\section{GOLES Y NACIONALISMO: FÚTBOL EN EL PAÍS DE "LA ROJA"}

El fútbol, como el olimpismo (De Moragas 2003: 612), es un hecho nacional innegable. Es dentro del marco del estado-nación que se organizan las competiciones. Incluso los torneos internacionales tienen un fuerte componente nacional. De hecho, destaca precisamente como excepción la participación del Derry City FC en la liga de la República de Irlanda y esta tuvo que contar con el permiso especial de la federación nordirlandesa y de la FIFA. Al fin y al cabo,
este ensamblaje entre fútbol $\mathrm{y}$ nacionalismo es claramente reconocible en el marco en que, desde un principio, se organizó el fútbol. La FIFA se organizó como una institución internacional que agrupaba expresamente a federaciones nacionales. Así, contribuía al proceso de nacionalización del fútbol, no solo al dedicarse a regular la

\footnotetext{
${ }^{6}$ Sin ir más lejos, la celebración de la Supercopa de España de 2020 en Arabia Saudí, a cambio de dinero, buscaba legitimar una monarquía caracterizada por violaciones reiteradas de derechos humanos.
} 
práctica del fútbol a escala mundial, sino también al dedicarse a organizar encuentros entre selecciones nacionales (Llopis 2006: 4041).

La FIFA, en consecuencia, en general excluye federaciones que no sean propias de algún estado-nación reconocido a escala internacional (pocos no están afiliados a la FIFA). Así, tan solo permite la excepción británica, país fundador del fútbol (con Inglaterra, Escocia, Gales e Irlanda del Norte), y aquellas federaciones que los estados han permitido participar a una parte de su territorio (usualmente de ultramar), como Islas Vírgenes norteamericanas, Puerto Rico y Samoa norteamericana (EE.UU.); Tahití y Nueva Caledonia (Francia); Islas Feroe (Dinamarca); Aruba y Curaçao (Reino de los Países Bajos) y Anguilla, Bermudas, Gibraltar, Islas Caimán, Islas Turks y Caicos y Montserrat (Reino Unido). Solo hay dos casos con soberanía disputada, Taipéi (República de China) y, después de un largo camino, en 1998, Palestina. Otro caso es el de las excolonias de Honk Kong y Malao, con existencia previa (1954 y 1978 respectivamente) a la incorporación en China (República Popular). De hecho, "uno de los atributos de la independencia de un Estado-nación es precisamente el equipo-nación, depositario de un enorme caudal simbólico y síntesis de las "grandes virtudes patrióticas" (Ramonet 1999b: 136).

De hecho, algunas propuestas alternativas no han terminado de cuajar, como cinco torneos Viva World Cup (de 2006 a 2012), campeonato de federaciones no estatales organizado por la NF-Board, y dos copas mundiales ConIFA celebradas en Laponia (2014) y Abjasia (2016). Otro intento fue la FIFI Wild Cup 2006 (Hamburgo). Por otra parte, en agosto de 1934 se celebró una Copa del Mundo de fútbol obrero como alternativa a la FIFA, que no tuvo continuidad.

En este sentido, las selecciones estatales masculinas de fútbol son uno de los mecanismos, bastante eficaces por cierto, de nacionalización social, de construcción de un nosotros que lucha entre iguales (en competiciones internacionales, es decir, entre nacionales) para conseguir la gloria en un campo bélico metafórico. De hecho, fue el régimen fascista de Benito Mussolini el que

descubrió los efectos propagandísticos del deporte en las diferentes competiciones [...]. La selección se convirtió en la selección nacional, elemento básico de cohesión de una sociedad diversa y plural como la italiana [...] la parte se convirtió en el todo. Por ejemplo, la selección española se convirtió en España, en adelante enfrentada, no a otra selección, sino a otro Estado-nación. [...] No fue un equipo el que 
ganaba sino un país, una nación, un Estado. El nacionalismo deportivo había nacido como elemento simbólico (Colomé 2007: 378379).

Al final, igualmente que otros mecanismos, como la literatura, la música y el cine, el deporte se nacionalizó al atribuir rasgos patrióticos a jugadores y equipos, que devinieron incluso "estilos nacionales típicos" o genuinos, con independencia de su veracidad (Quiroga 2014: 23-24, 27). No en balde, en 2014 casi cuatro de cada cinco españoles afirmaban sentirse muy o bastante orgulloso cuando un deportista español o una selección española realiza una buena actuación en un campeonato deportivo. En este éxito nacionalizador los medios de comunicación han tenido un papel protagonista. Y cada vez más. De hecho, "Internet facilita experimentar la nación por medio del fútbol las veinticuatro horas del día y los siete días de la semana" (Quiroga 2014: 33).

Por otro lado, la práctica ausencia de selecciones subestatales en competiciones oficiales han convertido varios clubes de fútbol en refugio de identidades colectivas regionales y/o nacionales sin estado. Cuando existía Yugoslavia, el Dinamo de Zagreb era un club que canalizaba el nacionalismo croata, análogamente a como en la URSS el Dinamo Tbilisi simbolizaba el nacionalismo georgiano y el Ararat Yereven el armenio. De hecho, "las luchas de esos clubes regionalistas contra los de la capital han sido tensas y a veces violentas, mientras que su participación en las competiciones europeas ha ofrecido en estas regiones una oportunidad de proyectarse internacionalmente" (Shaw 1987: 184).

En un sentido relativamente parecido, el fútbol también ha sido una plataforma contra el colonialismo. Por ejemplo, el Mouloudia Club de Argel fue un instrumento de los nacionalistas argelinos (Usall 2011: 18-19). En 1958 el Frente de Liberación Nacional argelino conformó un equipo con jugadores con cierto renombre que habían "desertado" de la liga francesa y, a pesar de la activa oposición de la FIFA, debido a las presiones francesas, hizo una gira mundial con el objetivo de contribuir a la independencia de Argelia. Una vez lograda esta, no tardó a ser aceptada en la federación con sede en Zúrich.

Hay que destacar que no solo es que la FIFA se organiza de acuerdo con los estados-nación, es que el fútbol es un factor muy importante de la nacionalización de los estados, les otorga legitimidad y verosimilitud internacional: 
El equipo nacional no es simplemente el resultado de la creación de un Estado: a menudo ayuda a forjar la nación [...]. El fútbol, encarnación de un Estado, que es la imagen simbólica de la nación, apreciado casi universalmente, contribuye con mucho a la imagen y popularidad de un país, al mismo nivel que los factores culturales (Boniface 1999: 92, 96).

En España, lógicamente, el fútbol también se ha asociado a identidades nacionales. En concreto, el nacionalismo español y los nacionalismos sin estado han usado este deporte para canalizar sus reivindicaciones. El actual rey Felipe VI, durante el discurso de concesión del Premio Príncipe de Asturias 2010 a la selección española masculina de fútbol, declaró que "nos hicisteis sentir la emoción y el orgullo de ser españoles. De pertenecer a una gran nación". Al respecto, la potencia homogeneizadora del Estado-nación ha sido y es muy superior y por este motivo ha utilizado el deporte con creces. De hecho, el artículo 6.1 de la vigente ley española 10/1990, de 15 de octubre, del deporte afirma que

el deporte de alto nivel se considera de interés para el Estado, en cuanto que constituye un factor esencial en el desarrollo deportivo, por el estímulo que supone para el fomento del deporte base, en virtud de las exigencias técnicas y científicas de su preparación, y por su función representativa de España en las pruebas o competiciones deportivas oficiales de carácter internacional (las cursivas son mías).

Al final, en consecuencia,

el nacionalismo español ha utilizado el deporte como exponente de su ideología. Loar las victorias o derrotas como hazañas bélicas ha sido un componente fundamental en el intento de cohesionar la sociedad española, diversa, plural y plurinacional, bajo los colores representativos del conjunto de España (Colomé 2007: 381).

Los campeonatos de "la" selección en la Eurocopa de 2008 y 2012 y al Mundial de 2010 no han hecho sino exacerbar el uso político (Quiroga 2014: 137-170). Ciertamente, el uso del nacionalismo español del fútbol es histórico. En 1903 se organizó un Campeonato de España que muy poco después se convertiría en la Copa de Su Majestad el Rey (entonces Alfonso XIII) y en 1928 se estableció una 
Liga Nacional, solo interrumpida por la guerra civil española, que ha tenido importantes efectos nacionalizadores al crear "una esfera cultural de ámbito nacional con un enorme impacto social" (Sanz 2012: 421).

Asimismo, la medalla de plata en los Juegos Olímpicos de Amberes de 1920 dio pie al mito de la "furia española", que en las narrativas belga y holandesa significaba brutalidad, pero en España, contrariamente, valentía, coraje, intenso deseo de ganar y virilidad (Quiroga 2014: 40-41, 46). Manuel Azaña, presidente de la República Española, fue uno de los que pensaba que el deporte vendría a servir a la construcción nacional de España (Colomé 2007: 381).

Por otro lado, atendiendo al interés que tuvo el régimen franquista por controlar y dirigir el deporte en España (Santacana 2005: 30) que, de hecho, quedó subordinado al Estado (Llopis 2012: 288), no es de extrañar que instrumentalizara el fútbol hasta el extremo que el historiador Paul Preston consideró que "formaba parte del tejido social y político de la dictadura" (Shaw 1987: 12). Todavía más, "el franquismo usó el fútbol como medio de nacionalización de masas en una sociedad eminentemente rural y con déficits educativos profundos" (Quiroga 2014: 53).

Al respecto, cabe recordar el uso propagandístico del gol de Zarra contra Inglaterra o el de Marcelino que valió la Eurocopa de 1964 nada más y nada menos que contra la selección soviética. No en balde, el decreto de creación de la Delegación Nacional de Deportes explicitaba que

la política del Estado falangista, orientada hacia la unidad y fortalecimiento de cuantas actividades conduzcan a la más firme potencia de la Patria, no puede descuidar en modo alguno el deporte, en qué [sic] encuentra uno de los principales instrumentos para la entera educación del hombre español (Santacana 2005: 32).

Por otra parte, igualmente que el fascismo italiano obligó a italianizar el vocabulario inglés y el histórico calcio sustituyó al foot-ball (Colomé 2007: 378), el régimen franquista ocupó y sustituyó los nombres de varios clubes de fútbol, como el Valencia Foot-ball Club (VFC), el Foot-ball Club Barcelona (FCB) y el Athletic Club por respectivamente Valencia Club de Fútbol (VCF), Club de Fútbol Barcelona (CFB) y Atlético de Bilbao (los dos últimos recuperaron el nombre en la década de los setenta. El Valencia, sin embargo, no). Incluso algunos clubes incorporaron el término balompié en su nombre, como el Real Betis Balompié o el Albacete Balompié. 
Con la recuperación de la democracia esta instrumentalización del fútbol no haría, con otras maneras, sino continuar o incluso intensificarse. De hecho, "desde principios de este siglo se ha producido un reforzamiento del tono nacionalista en la cobertura de la selección por los mass media” (Sanz 2012: 430).

Contrariamente, los nacionalismos periféricos han visto seriamente limitadas las posibilidades de participar en competiciones internacionales. Las participaciones de los combinados de fútbol de Cataluña o del País Vasco (o de Euskal Herria), en general, no han pasado de partidos amistosos y, en general, han sido reducidas a un único partido anual, normalmente en fechas navideñas, debido a la férrea oposición de la Federación Española de Fútbol y del gobierno español. Esta oposición ha ido acompañada de una retórica contundente e incluso ridiculizante. Por ejemplo, el portavoz del gobierno de José María Aznar entre 1996 y 1998, Miguel Ángel Rodríguez, declaró que

Este gobierno no va a destrozar la selección española de fútbol. [...] Si tan preocupados están por un deporte que, por cierto, no es español, que es inglés, [...] que impidan a los equipos de su comunidad que contraten a entrenadores y jugadores extranjeros. $\mathrm{Y}$, ya puestos a decir más sandeces, que sólo vayan a los estadios los nacidos en la ciudad, con lo cual terminarán jugando a las canicas (Gómez 2007: 82-83).

No han sido solo los partidos conservadores españoles quienes se han negado obstinadamente a esta participación. Jaime Lissavetzky, secretario de estado para el deporte de 2004 a 2011 con los gobiernos de José Luis Rodríguez Zapatero, afirmó que

un todo, España, nunca se puede enfrentar a una parte, Cataluña. Como nunca se han enfrentado Escocia o Gales con Gran Bretaña. No es posible. España es el Estado español y le representa su selección. No se producirá nunca un España-Cataluña, nunca (Gómez 2007: 104).

Históricamente se decía que la soberanía nacional se corporeizaba, además de en un territorio, en una moneda y un ejército. Quizás ya ha llegado la hora de considerar la selección masculina de fútbol como un factor tan o más importante. 


\section{EL REAL MADRID Y ESPAÑA}

El RM se ha identificado históricamente y, específicamente, a partir de la década de los cuarenta del siglo XX, con España y, en concreto, con la concepción castellanocéntrica y centralista del estado. No en balde, el himno madridista empieza con una referencia a España, para mostrar la voluntad de exceder el espacio territorial madrileño e incluso castellano: "De las glorias deportivas / que campean por España / va el Madrid con su bandera / limpia y blanca que no empaña". Incluso ha sido considerado por las instancias de poder como el club que ha representado a la "nación". Ya en 1904, en la reunión inaugural de la FIFA, el delegado español era del Madrid FC (Burns 2013: 67). De hecho, "el Madrid continúa estando dónde ha sido siempre: en el poder" (Aleixandre 2017: 77).

$\mathrm{Al}$ respecto, el rey Alfonso XIII concedió el derecho de nombrarse Real Madrid en 1920 y en 1923 el príncipe Don Gonzalo hizo la inauguración del estadio de Ciudad Lineal con el grito que permanecería: “¡Hala Madrid!”. Desde este club incluso se ha utilizado la retórica que habría sido una entidad históricamente al servicio de España. El durante décadas directivo Raimundo Saporta no pudo explicarlo más claro:

El Real Madrid es y ha sido político. Ha sido siempre tan poderoso por estar al servicio de la columna vertebral del Estado. Cuando se fundó en 1902 respetaba a Alfonso XIII, en el 31 en la República, en el 39 al Generalísimo, y ahora a su Majestad Juan Carlos. Porque es un Club disciplinado y acata con lealtad a la institución que dirige la nación (Shaw 1987: 13).

En realidad, España se ha servido del Madrid y el Madrid de España, en una relación simbiótica. Particularmente, a pesar de que algún autor lo niega (Bahamonde 2002), el RM fue el club preferido del franquismo y lo usó para mitigar el aislamiento internacional a cambio de beneficiarse de las simpatías del régimen (Quiroga 2014: 59). De hecho, este club de la capital del estado asumió la "representación" de España en una coyuntura en que la selección masculina de fútbol fracasaba una y otra vez. El régimen dictatorial hizo incluso un uso explícito de esta casi identificación RM-España para mejorar su imagen exterior. Por ejemplo, en 1959 el ministro secretario del Movimiento José Solís se dirigió a los jugadores madridistas con esta retórica:

vosotros habéis hecho mucho más que muchas embajadas desperdigadas por esos pueblos de Dios. Gente que nos odiaba ahora 


\begin{abstract}
nos comprende, gracias a vosotros, porque rompisteis muchas murallas... Vuestras victorias constituyen un legítimo orgullo para todos los españoles, dentro y fuera de nuestra patria. Cuando os retiráis a los vestuarios, al final de cada encuentro, sabed que todos los españoles están con vosotros y os acompañan, orgullosos de vuestros triunfos, que tan alto dejan el pabellón español” (Shaw 1987: $18)$.
\end{abstract}

Aun así, no siempre esta identificación del Madrid con el nacionalismo español y España se hace patente. A veces, se trata de disimular con pretensiones europeístas, universalistas o incluso de eficacia empresarial. A modo de ejemplo, sin que a los periodistas que lo entrevistaron les extrañara o pidieron alguna matización, el que fue presidente del RM entre 2006 y 2009, Ramón Calderón, declaró que "el Madrid, a diferencia otros equipos, como el Sevilla o el Valencia, no se identifica con regionalismos, sino con una idea global: el éxito. Es por eso la famosa frialdad del Bernabéu".7

Contrariamente al RM, el Athletic Club y la Real Sociedad de San Sebastián y el FCB, entre otros de menos importancia, han sido instituciones implicadas, respectivamente, con más o menos intensidad según cada periodo, con el nacionalismo vasco y catalán. Durante el franquismo, con una represión concienzuda de estos, estos clubes fueron una vía de canalización de las reivindicaciones vasquistas y catalanistas (Shaw 1987: 183).

En el caso del FCB el régimen franquista incluso hizo desaparecer la bandera "catalana" del escudo del cuartel superior entre 1941 y 1949. De hecho, entre 1939 y 1946 el club estuvo "intervenido" por el franquismo (Luque y Finestres 2014). El diario madrileño Marca sugirió cambiar de camiseta y de nombre, proponiendo el de España (Santacana 2005: 35). Asimismo, se designaron directamente hasta 1953 los presidentes del club.

El del Athletic, sin embargo, fue un caso paradójico, ya que no solo los nacionalistas vascos lo han reivindicado. Acabada la guerra civil y con el club convenientemente depurado, el propio Francisco Franco lo alababa como un "equipo español de pura sangre, agallas y descaro. De hecho, era su equipo

7 El 'dosier Calderón': así se destruye a un presidente del Real Madrid, El Confidencial, 15-9-2019:

https://www.elconfidencial.com/deportes/futbol/2019-09-15/ramon-calderon-realmadrid-florentino-perez_2226183/, consulta noviembre 2020. 
preferido antes de la época dorada del Real Madrid" (Burns 2013: 80). El nacionalismo español conservador, curiosamente, continúa reivindicando el Athletic como el único club formado exclusivamente por jugadores españoles (vascos).

Los nacionalismos catalán, vasco y cualquier otro peninsular sin estado han sido retroalimentados por parte del nacionalismo español. Este, a pesar de negarse, por medio de la estrategia del nacionalismo banal que ha estudiado Michael Billig (2006), a menudo es responsable de las reacciones periféricas (Colomé 2007: 381).

Y también al revés. Por ejemplo, el columnista de ABC Antonio Burgos se oponía a las selecciones de Cataluña y Euskadi y a su vez mostraba su entusiasmo por la España madridista de este modo:

Con su separatismo y su odio a España, las selecciones nacionales de la Señorita Pepis, la del Señor Ibarreche y la del Señor Maragall, han conseguido hacer odiosos a los equipos vascos y catalanes. De aquel Athlétic de Bilbao que caía simpático a España entera porque no fichaba extranjeros hemos pasado a éste, que lo que no ficha son españoles nacidos fuera de Vascongadas. El que cae simpático ahora en la España no separatista es el Real Madrid, símbolo de la nación (Gómez 2007: 187-188).

Las identidades, a pesar de que no son simétricas, son resultado de un proceso especular.

\section{EL DUOPOLIO MADRID-BARÇA}

La rivalidad futbolística entre el RM y el FCB es la más sentida en España, como es conocido, por muchos motivos que escapan a las posibilidades de este artículo. Esta no tiene parangón, por ejemplo, en una liga como la inglesa. Ha contado con muchos episodios a lo largo de la historia, particularmente durante el franquismo, con el Madrid como equipo próximo al régimen y el entonces BCF, identificado con Cataluña y, en particular en el periodo final de la dictadura, con una España democrática. Como se ha dicho, las identidades y los estereotipos son móviles y dependen del contexto. No deja de ser curioso, por ejemplo, que "el FC Barcelona, el equipo de los extranjeros, devenga el símbolo de Cataluña, mientras que el RCD Espanyol, el equipo de los autóctonos, representará el anticatalanismo" (Colomé 1999: 171). 
Sin embargo, la rivalidad barcelonesa pasó a un segundo plano durante el franquismo y dejó el protagonismo al antagonismo entre RM y FCB (p. 173), que ha sido atizada incluso por presidentes. Santiago Bernabéu declaró en 1968, después de perder una final de copa ante el FCB en casa, que
A Vilà-Reyes yo le admiro. Sólo por presidir en Cataluña un club que lleve el nombre de Español ya es digno de admiración [...]. Y no están en lo cierto los que dicen que no quiero a Cataluña. La quiero y la admiro a pesar de los catalanes (Santacana 2005: 67).

Esta "chulería" atribuida al madridismo fue aprovechada por el FCB para proponer un contramodelo, que en parte funcionó, aunque ha llegado a devenir una grotesca exageración, puesto que se ha llegado a considerar como "la sublimación ética del pueblo catalán en un equipo de fútbol" (Colomé 1999: 169). Así, el FCB sería más que un club. ¿Pero qué sería este plus? Pues, además de una representación de Cataluña (de la Cataluña democrática y catalanista, se entiende), contaría una reacción al madridismo "oficial" del franquismo que le otorgaría un aura "rebelde" (Santacana 2005: 137).

Esta rebeldía, sin embargo, resultaba más creíble durante el franquismo que actualmente. De hecho, el FCB, juntamente con el RM, se ha convertido en uno de los dos clubes de fútbol más poderosos del mundo. Con independencia de cómo se evalúe esta rivalidad, parece indudable que ha sido beneficiosa para los dos y en la Liga española ha acabado para imponerse un tipo de duopolio que se traga buena parte de la diversidad del fútbol estatal (y de sus beneficios económicos). Por ejemplo, puede servir de dato que, de los veinte primeros campeonatos de liga en el siglo XXI, entre ambos clubes han ganado diecisiete, el 85\%. Solo el VCF en las temporadas 2001-2002 y 2003-2004 y el AM en la 20132014 han conseguido matizar esta hegemonía aplastante.

Ciertamente, según los datos que disponemos, la mayoría de los seguidores son del RM y del FCB. A pesar de que no fue el equipo principal de la ciudad de Madrid hasta el franquismo (Santacana 2005: 26), España es mayoritariamente madridista. En 2014 el 37'9\% de los futboleros tenían al RM por el equipo por el que sentían más simpatía y otro 7\% como segunda opción. ${ }^{8}$ En 2007 contaba con el apoyo del 32 ' $8 \%$ como primer equipo y del 6 ' $8 \%$ como segundo. Sin embargo,

\footnotetext{
${ }^{8}$ Hay que tener en cuenta que la pregunta $22 \mathrm{~b}$ del cuestionario permite un máximo de tres respuestas. Un mismo forofo, pues, puede mostrar simpatías por hasta tres equipos.
} 
hay que señalar que es una mayoría simple y que, a pesar del apoyo nítido de los grandes medios de comunicación españoles, apenas supera una tercera parte del total de seguidores.

Por otro lado, el FCB contaría con un 25'4\% de seguidores y otro 63\% como segundo (un porcentaje en apariencia estable, puesto que en 2007 era prácticamente idéntico). Esto significaría que entre ambos equipos concentrarían dos terceras partes del total de los forofos al fútbol en España (63'3\%). Ciertamente es una alta cantidad para una liga de veinte equipos, pero está significativamente por debajo de los campeonatos de liga conseguidos por los dos en esta centuria, lo cual es indicativa del poder (futbolístico pero no solo) que concentran. De hecho, son los dos clubes de fútbol con más ingresos del mundo de acuerdo con el portal Deloitte, con 750 y 690 millones de euros respectivamente en 2018, y dos de los cuatro clubes deportivos más valiosos del mundo en 2019, según Forbes, con 4.239 y 4.021 millones de dólares cada uno. No en balde, en 2007 (en 2014 no se preguntó) prácticamente tres cuartos de la población estaba muy o bastante de acuerdo con la afirmación que "en el fútbol profesional se mueve mucho dinero y existe corrupción”. Asimismo, un 47'6\% consideraba que "las decisiones de los árbitros siempre favorecen a los mismos y acaban para alterar el resultado del campeonato” frente a un 31'6\% que no.

El tercer, cuarto y quinto equipos con más seguidores, a mucha distancia, sin embargo, de los dos primeros, serían el AM (6'1\% como primero y $8^{\prime} 3 \%$ como segundo), el VCF (3'5 y 1'9\%) y el Athletic Club (3’3\% y 2'5\%). El orden de estos tres, se ha modificado, probablemente como consecuencia de los distintos resultados clasificatorios (a pesar de que también puede deberse al error muestral): en 2007 el VCF era el tercero (5’3\% y $2{ }^{\prime} 8 \%$ ), el Athletic cuarto (5'1\% y 2'2\%) y el AM quinto (4'3\% y 3'4\%).

\section{UN CLUB REGIONALISTA: EL CASO DEL VALENCIA CF}

Están peor estudiadas las identidades colectivas de los otros clubes de la liga española. Sin embargo, contamos con algunos estudios monográficos (como, por ejemplo, Flor 2020) que pueden servirnos de guía. Estos "otros" pueden ayudar a comprender mejor la complejidad identitaria del fútbol español. Aquí se analizará brevemente el caso del VCF como contrapunto al RM y al FCB.

El VCF, a diferencia del FCB, no ha sido un club nacionalista "periférico", como tampoco lo es mayoritariamente la sociedad valenciana. Sí ha sido y es un club regionalista valenciano, lo cual le ha hecho chocar, además de la rivalidad 
estrictamente deportiva, con el RM, que habría encarnado, como se ha mencionado, el centralismo y la España unitarista. Es importante destacar que, a diferencia de visiones muy unitaristas que perciben en los regionalismos protonacionalismos, la construcción de la región normalmente no solo no es incompatible sino que refuerza la construcción nacional. De hecho,
la creación o fortalecimiento de identidades provinciales y regionales basadas en el deporte no obstaculiza el fomento de los sentimientos nacionales. Al contrario, la construcción de identidades locales, provinciales y regionales por medio del fútbol ha reforzado las nacionales (Quiroga 2014: 25).

El VCF se ha identificado con la ciudad, la provincia y la comunidad autónoma que lleva su nombre. No es la táctica de usar la sinécdoque patrimonio exclusivo de este club. Como ya se ha mencionado, el FCB también la usa respecto de Cataluña y el Madrid respecto de España. Así, no es extraño por ejemplo que el expresidente Manuel Llorente declarara que

en el Valencia Club de Fútbol nos sentimos embajadores de la Comunidad Valenciana, sabemos que tenemos la responsabilidad de representar no solo a un club y su afición, sino también en una tierra, en una ciudad que nos da nombre y con la cual se identifica plenamente a nuestro equipo. ${ }^{9}$

El madridismo, pues, se ha configurado como la alteridad principal de los seguidores del VCF, a pesar del usual desprecio madridista por el club valenciano. Por ejemplo, el escritor madridista Javier Marías lo describe así: "el Valencia es a la vez fanfarrón y cohibido, es decir, se cohíbe demasiado en cuanto la fanfarria se calla (y no hay ninguna que dure todo un campeonato)" (2000: 96).

Esta actitud, considerada soberbia por los valencianistas, retroalimenta el antimadridismo. Además, la afición madridista ha mostrado explícitamente alguna vez rechazo al VCF por motivos políticos e identitarios. Durante la transición democrática el club recuperó la equipación con la bandera valenciana como segundo equipaje y lo proyectó como icono representativo. Este hecho llegó a ser visto en el Santiago Bernabéu como una provocación regionalista y/o

\footnotetext{
${ }^{9}$ Las Provincias, 27-2-2012, p. 11.
} 
nacionalista peligrosa para la unidad del estado. El 6 de noviembre de 1977 el VCF vistió la "señera" y fue recibido con

una bronca ensordecedora, probablemente una de las mayores que el club de Mestalla haya escuchado en su historia. [...] Hubo algunos incidentes en el graderío y el partido se desarrolló en medio de un clima crispado. Los directivos valencianistas presentes en el palco también fueron increpados por algunos exaltados que se dirigían a ellos con gritos contra el supuesto separatismo valenciano y consignas de "Viva España (Lloret 2009: 102 y 104).

Quizás con la excepción del FCB durante la época de la transición, los seguidores del VCF han tenido, por tanto, como adversario fundamental al RM (Lloret 2009: 41). De hecho, en un intento diferenciacionista respecto a este club, durante la presidencia de Francisco Roig se recuperó el color negro de las calzas y se amplió al pantalón (Lloret 2009: 109). Los símbolos no acostumbran a ser neutrales, puesto que los grupos sociales, de manera distinta, los dotan de significación, con independencia de las intenciones originarias de quienes los crearon.

El diferenciacionismo hacia el RM no se limita al cromatismo. También incluye valores e incluso "ideología". Así, si el Madrid representaría la España castellanocéntrica y "oficial”, el Valencia aspiraría a representar, por lo menos de manera parcial, la España "real", frente al Madrid político, del poder, la València meritocrática, civil y empresarial. El mencionado expresidente Llorente declaró que

nuestros problemas los tendremos que solucionar nosotros, ni en Madrid ni en Bruselas están pensando a hacerlo, al menos como prioridad. [...] el valenciano es un pueblo muy trabajador, muy apasionado en todo el que hace y, por lo tanto, muy competitivo. El valenciano es ganador. [...] Y lo tendremos que hacer con esa cultura casi olvidada del esfuerzo y del sacrificio. ${ }^{10}$

La realidad, obviamente, es mucho más compleja que este tipo de discursos. Aun así, esta retórica presenta una influencia innegable.

${ }^{10}$ Las Provincias, 27-2-2012, p. 11. 
Por otra parte, el VFC participó del enfrentamiento identitario valenciano durante la transición democrática. ${ }^{11} \mathrm{El}$ regionalismo "sano" que promovía el franquismo en el País Valenciano fue contestado por el antifranquismo valencianista, en particular a partir de los sesenta, con el desarrollo del "paradigma fusteriano" (Alcaraz 1985), una propuesta nacionalista valenciana progresista o de izquierdas y, por tanto, contraria al nacionalismo español y, específicamente, al regionalismo conservador. Durante la transición, para decirlo de manera muy esquemática, se enfrentaron estas dos visiones de la identidad valenciana (Flor 2011: 291-315).

El VCF no fue ajeno a esta disputa. De hecho, el club se situó, con más o menos intensidad y particularmente durante las presidencias de José Ramos Costa (1976-1983) y Vicente Tormo (1983-1986), junto al regionalismo anticatalanista (Lloret 2009: 36). Ciertamente, el anticatalanismo no es patrimonio exclusivo de la sociedad valenciana. De hecho, es una reacción nacionalista española contra el catalanismo o el nacionalismo catalán que se da tanto en Madrid, València, como incluso en la misma Barcelona (Flor 2014). Pero en València ha tenido formas propias. Lo cierto es que la actitud del club fue parcialmente diferente de la de otros con tensiones identitarias análogas, como el Osasuna:

es evidente que Osasuna, como Club de fútbol, no representaba directamente una visión concreta de Navarra, pero sí que Osasuna sirvió para encarnar visiones diversas de Navarra, fundamentalmente navarrista una, nacionalista vasca otra" (Caspistegui 2001: 213).

De hecho, la rivalidad histórica entre el VCF y el FCB, propia de dos equipos que competían por los mismos títulos, no se convirtió en propiamente política hasta después de la muerte de Francisco Franco (Lloret 2009: 36). Desde la transición las consignas anticatalanistas han sido cierta constante en Mestalla, particularmente en los enfrentamientos con el FCB. Pasada la efervescencia de la transición y, en menor manera, de los ochenta la afición valenciana también se relajó en este asunto a pesar de que no lo abandonó por completo.

${ }^{11}$ Aunque hunde sus raíces por lo menos en la década de los sesenta del siglo XX (Flor 2015). 


\section{CONCLUSIONES}

El fútbol, como se ha visto, es algo más que una simple actividad física regulada. También forma parte de la vida de mucha gente. De hecho, "la razón por la cual el fútbol resulta tan importante para tantos de nosotros apunta precisamente a la experiencia asociativa que constituye su núcleo, y al vívido sentido de comunidad que proporciona" (Critchley 2018: 19).

Este deporte significa para muchas personas una experiencia identitaria potente, bien como jugador o como seguidor, ya que puede en muchos casos facilitar un sentido de pertenencia y contribuye a tejer una red de relaciones sociales. $Y$, en concreto, también presenta un importante factor de identidad personal para muchas personas. Por eso, buena parte de los seguidores de un club permanecen fieles a lo largo de su trayectoria vital, incluso teniendo que soportar decisiones que no comparten en absoluto.

En este contexto, por lo menos en buena parte del continente europeo, de pérdida de adscripción identitaria de factores históricos muy importantes como el trabajo o la religión, otros mecanismos han venido en parte a sustituirlos. Y el deporte es uno de los importantes. De hecho, el fútbol es un fenómeno de masas que ha ayudado a conformar diferentes identidades colectivas. Los diferentes nacionalismos, regionalismos e incluso localismos han canalizado sus reivindicaciones por medio de selecciones masculinas y/o clubes de fútbol. Está por ver si el ascendente fútbol femenino tendrá una potencia identitaria análoga.

El fútbol, además, mantiene una relación innegable con las sociedades en que se inserta y, en concreto, con las identidades políticas y culturales. El exjugador del RM y exentrenador de la selección española Vicente del Bosque reconoció que "el fútbol y la política van por caminos paralelos: el fútbol tiene una ascendencia social incuestionable” (Burns 2013: 349).

El fútbol, a pesar de su siglo y medio de historia, tiene un final abierto. Y este todavía no está escrito. Lo que sí que sabemos es que los regímenes políticos de todo tipo "politizan" el fútbol. Al final, "la historia del fútbol es la de una recuperación y de reinvenciones permanentes" (Correia 2019: 18).

No en balde, por ejemplo, en África se estableció por los colonos para "civilizar" a los colonizados y estos lo transformaron en un deporte emancipador contra el colonialismo (p. 237). El fútbol es mucho más que un terreno de la nostalgia, tiene una gran importancia en la conformación de identidades colectivas. 


\section{BIBLIOGRAFÍA}

ALCARAZ, M. (2017): Cuestión nacional y autonomía valenciana, Instituto Juan Gil Albert, Alicante.

ALEIXANDRE, JV. (2017): La inteligencia a sus pies, Institució Alfons el Magnànim, València.

ANDERSON, B. (2007): Comunidades imaginadas. Reflexión sobre el origen y la difusion del nacionalismo, Fondo de Cultura Económica, México DF.

ARMSTRONG, G. y GIULIANOTTI, R. (eds.) (1999): Football cultures and identities, Macmillan, Houndsmills.

AUGÉ, M. (1999): “¿Un deporte o un ritual?”, Fútbol y pasiones políticas, Debate, Barcelona.

BAHAMONDE, Á. (2002): El Real Madrid en la historia de España, Taurus, Madrid.

BILLIG, M. (2014): Nacionalismo Banal, Capitán Swing, Madrid.

BONIFACE, P. (1999): “Geopolítica del fútbol”, Fútbol y pasiones políticas, Debate, Barcelona.

BROCHAND, P. (1999): “Entre lo nacional y lo transnacional”, Fútbol y pasiones políticas, Debate, Barcelona.

BROHM, J.M. (1999): "Una multinacional del beneficio", Fútbol y pasiones políticas, Debate, Barcelona.

BROMBERGER, CH. (1999): "El revelador de todas las pasiones", Fútbol y pasiones políticas, Debate, Barcelona.

BURNS, J. (2013): De Riotinto a la roja. Un viaje por el fútbol español (1887-2012), Contra, Barcelona.

CASPISTEGUI, F.J. (2001): “Osasuna y Navarra entre primera y segunda división”, Guerras danzadas. Fútbol e identidades locales y regionales en Europa, Eunsa, Pamplona.

CRITCHLEY, S. (2018): En qué pensamos cuando pensamos en fútbol, Sexto piso, Madrid.

COLLINS, R. (2005): Interaction Ritual Chains, Princeton University Press, Princeton.

COLOMÉ, G. (1999): “Conflictos e identidades en Cataluña”, Fútbol y pasiones políticas, Debate, Barcelona. 
COLOMÉ, G. (2007): "Una nota sobre deporte y política", Nacionalismo español. Esencias, memorias e instituciones, Catarata, Madrid.

CORREIA, M. (2019): Una història popular del futbol, Tigre de Paper, Barcelona.

CURLETTO, M. A. (2018): Fútbol y poder en la URSS de Stalin, Altamarea, Madrid.

DE MORAGAS, M. (2003), "Olimpismo, deporte y mundialización", Hacia una Sociedad civil global, Taurus, Madrid.

DUNNING, E. (1999): Sports matters. Sociological studies of sport, violence and civilization, Routledge, Londres.

EDJOGO-OWONO, A. (2019): Indomable. Cuadernos de fútbol africano, Panenka, Barcelona.

ELIAS, N. y DUNNING, E. (2016): Deporte y ocio en el proceso de civilización, FCE, México DF.

FERNÁNDEZ, M. (2020): Fútbol y anarquismo, Catarata, Madrid.

FLOR, V. (2011): Noves glòries a Espanya. Anticatalanisme i identitat valenciana, Afers, Catarroja.

FLOR, V. (2014): “'Igual que Franco pero al revés": una aproximación sociológica al anticatalanismo en la España autonómica", Naciones y estado. La cuestión española, PUV, València.

FLOR, V. (2015): "El regionalismo banal y la construcción de la identidad valenciana autonómica. Una perspectiva desde la sociología histórica", Pensar con la Historia desde el siglo XXI, Universidad Autónoma de Madrid, Madrid.

FLOR, V. (2020): Nosaltres som el València. Futbol, poder $i$ identitats, Afers, Catarroja.

GALEANO, E. (1995): El futbol, a sol y sombra, Siglo XXI, Madrid.

GARCÍA FERRANDO, M. (2003): "Mundialización y deporte profesional", Hacia una Sociedad civil global, Taurus, Madrid. 
GÓMEZ, D. (2007): La patria del gol: fútbol y política en el Estado español, Alberdania, Irún.

HILL, D. (2010): Juego sucio. Fútbol y crimen organizado, Alba, Barcelona.

HOBSWAWM, E. (1979): “La culture ouvrière en Angleterre”, L'Historie, no 17.

LUQUE, X. y FINESTRES, J. (2014): El Barça segrestat. Set anys intervingut pel franquisme (1939-1946), Ara, Barcelona.

LLOPIS, R. (2006): “Clubes y selecciones nacionales de fútbol. La dimensión etnoterritorial del fútbol español”, Revista Internacional de Sociología, no 45 .

LLOPIS, R. (2012): "Futbol, identitat i ciutadania", DDAA: El planeta del futbol, Diputació de València, València.

LLORET, P. (2009): Crónica de un desencuentro. Valencia vs R. Madrid, Carena, València.

MARÍAS, J. (2000): Salvajes y sentimentales. Letras de fútbol, Aguilar, Madrid.

MaCFARQUHAR, N. (2010): Hezbolá le desea feliz cumpleaños. Encuentros inesperados en Oriente Próximo, Turner, Madrid.

PEINADO, Q. (2013): Futbolistas de izquierdas, Léeme, Alcalá de Henares.

QUIROGA, A. (2014): Goles y banderas: fútbol e identidades nacionales en España, Marcial Pons, Madrid.

RAMONET, I. (1999a): "Un hecho social total", Fútbol y pasiones políticas, Debate, Barcelona.

RAMONET, I. (1999b): “El fútbol es la guerra”, Fútbol y pasiones políticas, Debate, Barcelona.

REGUERA, G. (2008): "La identidad de los clubes de fútbol”, Cultura(s) del fútbol, Bassarai, Bilbao.

SANTACANA, C. (2005): El Barça i el franquisme. Crònica d'uns anys decisius per a Catalunya (1968-1978), Mina, Barcelona.

SANZ, J. (2012): "De la azul a "la roja". Fútbol e identidad nacional española durante la dictadura franquista y la democracia”, La nación de los españoles. Discursos y prácticas del nacionalismo español en la época contemporánea, PUV, València.

SHAW, D. (1987): Futbol y franquismo, Alianza, Madrid.

TURNER, V. (1974): Dramas, fields, and methafors. Symbolic action in human society, Cornell University Press, Ithaca, Londres.

USALL, R. (2011): Futbol per la llibertat, Pagès, Lleida. 
VÁZQUEZ MONTALBÁN, M. (1999): “El fútbol, la fascinación del planeta”, Fútbol y pasiones políticas, Debate, Barcelona.

WALTON, J.K. (2001): "Football and Identities: England and Spain", Guerras danzadas. Fútbol e identidades locales y regionales en Europa, Eunsa, Pamplona.

VIÑAS, C. (2019): Futbol al país dels soviets. Una eina al servei de la revolució, Tigre de Paper, Barcelona.

VIÑAS, C. y PARRA, N. (2017): St. Pauli. Otro fútbol es posible, Capitán Swing, Madrid.

Recibido: 15 de diciembre de 2020

Aceptado: 27 de mayo de 2021

Vicent Flor (València, 1971) es licenciado en ciencias políticas y sociología y en antropología social y cultural, ambas por la UNED, y doctor en sociología por la Universitat de València. Desde 2000 es profesor de sociología de la Universitat de València (ahora en excedencia) y desde 2015 director de la Institució Alfons el Magnànim. Ha trabajado de gestor cultural (conservador) en el Museo Valenciano de la Ilustración y la Modernidad de 1998 a 2015. Sus líneas de investigación principales se centran en temas de sociología política, de sociología de la cultura y de sociología del deporte. Además de diversos artículos en revistas académicas y capítulos en libros colectivos, es autor de los libros de Noves glòries a Espanya. Anticatalanisme i identitat valenciana (2011), Societat Anònima. Els valencians, els diners i la política (2015) y Nosaltres som el València. Futbol, poder i identitats (2020). vicent.flor@uv.es 